\title{
Investigations on Microwave-Assisted Synthesis of Carboxymethyl Cassia Gum
}

\author{
Manisha Sharma $^{1 \mathbb{D}}$, Rimpy ${ }^{1 \mathbb{D}}$, Shakuntla Verma ${ }^{1 \mathbb{D}}$, Tarun Kumar ${ }^{1 \mathbb{D}}$, Munish Ahuja ${ }^{1, *}{ }^{\mathbb{D}}$ \\ 1 Drug Delivery Research Laboratory, Department of Pharmaceutical Sciences, Guru Jambheshwar University of Science \\ and Technology, Hisar 125001, India \\ * Correspondence: munishahuja17@yahoo.co.in;
}

Scopus Author ID 7101943061

Received: 20.04.2020; Revised: 6.05.2020; Accepted: 7.05.2020; Published: 12.05.2020

\begin{abstract}
The objective of this study was to chemically alter Cassia gum by means of carboxymethylation reaction with the aid of microwave radiations, producing highly substituted carboxymethylated Cassia gum. The carboxymethyl substitution of Cassia gum was optimized using response surface methodology. The optimal parameters were found to be microwave power of $50 \mathrm{~W}$ and microwave exposure time of 7.36 minute which provided carboxymethylated gum with a degree of substitution of 2.5 (Predicted 2.3). Structural changes after carboxymethylation reaction were confirmed using Fourier-transform infrared and X-ray diffraction. Further, diclofenac sodium-loaded $\mathrm{Ca}^{2+}$ - gelled carboxymethylated Cassia gum beads were prepared. The effect of microwave exposure on beads was studied at different powers. However, no significant influence of microwave exposure on the release of diclofenac from beads was observed. The beads were observed to release diclofenac by zero-order kinetics with anamolous release mechanism. In conclusion, the microwave-assisted carboxymethyl modification of Cassia gum can be carried out to prepare modified gum with potential for use as matrix material for pharmaceutical applications.
\end{abstract}

Keywords: Cassia gum; Carboxymethylation; Microwave; Beads; Degree of substitution.

(C) 2020 by the authors. This article is an open access article distributed under the terms and conditions of the Creative Commons Attribution (CC BY) license (https://creativecommons.org/licenses/by/4.0/).

\section{Introduction}

The endosperm flour i.e. Cassia gum can be obtained from herbaceous perennial weed C. tora L. and C. obtusifolia L. after removing the germ (41\%) and hull (27\%) present in the seeds [1-3]. It is one of the lowest accessible polymers in India and research has shown that the backbone polysaccharide comprises 1-4 linked D-manopyranose and D-glucopyranose units. The gum comprising $75 \%$ of galactomannans have numeral properties such as thickening and gelling agent [2], good adsorbent, and coagulating/flocculating agent [4] and binding agent [5]. The applications of Cassia gum are limited because of its small water solubility, the dull colour of the polymer product, and its fast biodegradability [6]. Numerous findings have explored the alteration of Cassia gum in order to improve acceptability and gum quality [7]. These techniques include cyanoethylation [8-10], grafting [11], and carbamoylethylation [8-10, 12]. From various physico-chemical approaches, carboxymethylation modification is a widely used technique because of its low cost, easy processing and enhancing functional properties [13]. Basically, carboxymethylation is an etherification process in which hydroxyl group present in glucose get replaced with carboxymethyl group $\left(-\mathrm{CH}_{2} \mathrm{COO}^{-}\right)$[14]. Modified carboxymethyl polysaccharide is typically more dissolvable, low viscous and anionic than native polysaccharide. Furthermore, the anionic property imparted by carboxymethylation to 
polysaccharides paves the way for its development in the production of ionic polymeric materials [15-16]. So, carboxymethylation technique was utilized for enhancing the polysaccharide functionality.

On reviewing the literature, it was found that microwave assisted technology has been employed to modify the release behaviour of natural gum matrices by cross-linking. This high valued technique is used for the synthesis of polymers, organic, inorganic compounds and nanomaterials [17-18]. Considering the same, in the present work MW-assisted carboxymethyl modification of Cassia gum was attempted. The modification of Cassia gum was optimized using systematic Design of Experiment (DoE) approach, employing two-factor, three-level central composite experimental design. The modified gum was characterized by determining the degree of substitution, Fourier-transform infrared, X-ray diffraction studies. The modified gum was utilized to prepare ionically gelled beads with calcium chloride as ionic cross-linker and diclofenac as the model drug. Further, the effect of microwave exposure on beads was also studied to modify the release characteristics of Cassia gum by cross-linking.

\section{Materials and Methods}

\subsection{Materials.}

Cassia gum powder and diclofenac sodium were obtained as gift samples from Mahesh Argo Food Industries (Rajasthan, India) and Coax Bioremedies, (Hisar, India) respectively. Monochloroacetic acid was procured from Thomas Baker Chemicals Private Limited (Mumbai, India). Sodium hydroxide, glacial acetic acid and methanol were obtained from Sisco Research Laboratories Private Limited (Mumbai, India). Calcium chloride-dihydrate AR and hydrochloric acid were procured from S.D. fine chem. Ltd. (Mumbai, India).

\subsection{Methods.}

\subsubsection{Preparation of microwave assisted carboxymethyl Cassia gum.}

Microwave aided method was utilized to carboxymethylate Cassia gum. About $0.5 \mathrm{~g}$ of Cassia gum powder was mixed with $20 \mathrm{ml}$ of chilled sodium hydroxide $(45 \% \mathrm{w} / \mathrm{v})$. The same amount of aqueous monochloroacetic acid $(75 \% \mathrm{w} / \mathrm{v})$ was added up to the prepared solution of Cassia gum in the same vial by vortex shaker. The prepared blend was heated at $70^{\circ} \mathrm{C}$ with the aid of stirring at $1200 \mathrm{rpm}$ at different microwave power (50-150 W) with different time periods (2.5-7.5 minutes) (Monowave 200, Anton Paar, Austria). After microwave synthesis, the mixture was suspended in $20 \mathrm{ml}$ of methanol $(80 \% \mathrm{v} / \mathrm{v})$. The suspended precipitate, so collected, was filtered and washed with glacial acetic acid up to neutralization. Then, carboxymethyl Cassia gum was washed with aqueous methanol $(80 \%$ v/v) several times and dried at $80^{\circ} \mathrm{C}$ for $24 \mathrm{~h}$ in hot air oven [19].

\subsubsection{Experimental design.}

Microwave assisted carboxymethylation of Cassia gum was optimized using twofactor, three-level central composite design. To study the optimum combination of variables on carboxymethylated Cassia gum, the effect of factors i.e. microwave power $\left(X_{1}\right)$ and microwave irradiation time $\left(X_{2}\right)$ were used as independent variables and studied the degree of substitution which was chosen as a dependent variable. The impact of the independent variables was explored at three concentrations, i.e. small (-1), medium (0) and high $(+1)$. The 
experimental design and statistical analysis of results were carried out using Design Expert ${ }^{\circledR}$ software (version 11.0.0, Stat-ease Inc. Minneapolis, MN).

\subsection{Characterization of carboxymethylated Cassia gum.}

\subsubsection{Detection of degree of substitution.}

The degree of substitution (DS) was detected by acid wash method [20]. Accurately weighed carboxymethylated Cassia gum $(0.5 \mathrm{gm})$ was spread in $20 \mathrm{ml}$ of $\mathrm{HCl}$ reagent and sonication (Powersonic 405. Hwashin Technology Seoul. Korea) was done for 3-4 h. Separation of large particles was done through filtration, followed by washing with methanol $(70 \% \mathrm{v} / \mathrm{v})$ up to neutralization and dried at $80{ }^{\circ} \mathrm{C}$ in hot air oven. A weighed amount of carboxymethylated Cassia gum (0.3 gm) was dispersed in $10 \mathrm{ml}$ of methanol $(70 \% \mathrm{v} / \mathrm{v})$ and stirred for 30 minutes by adding a fraction of distilled water $(30 \mathrm{ml})$ and $0.5 \mathrm{~N} \mathrm{NaOH}(7.5 \mathrm{ml})$. Further, sonication was carried out for $4 \mathrm{~h}$ to solubilize the carboxymethylated Cassia gum completely. The excess of $\mathrm{NaOH}$ was back titrated with $0.5 \mathrm{~N} \mathrm{HCl}$. The degree of carboxymethylated Cassia gum was calculated as per the following equation given by Eyler et al. 1947 [21]:

$$
D S=\frac{0.162 \mathrm{~A}}{1-0.058 \mathrm{~A}}
$$

Where, $\mathrm{A}$ is milliequivalents of $\mathrm{NaOH}$ required per gram of the sample and the value of $\mathrm{A}$ was calculated using the following equation:

$$
A=\frac{\left(V_{\text {NaOH }} \times \mathrm{N}_{\text {base }}\right)-\left(V_{\text {acid }} \times \mathrm{N}_{\text {acid }}\right)}{\mathrm{W}}
$$

Where, $\mathrm{V}_{\text {base }}$ and $\mathrm{N}_{\text {base }}$ are volume and the normality of sodium hydroxide used while $\mathrm{V}_{\text {acid }}$ and $\mathrm{N}_{\text {acid }}$ are the volume and normality of hydrochloric acid used.

\subsubsection{Fourier Transform-Infrared spectroscopy (FT-IR).}

The Fourier transform infrared spectra of Cassia gum and carboxymethylated Cassia gum (IR-affinity-I, Shimadzu, Japan) were recorded using potassium bromide (KBr) disc method in the spectrum range between $4000 \mathrm{~cm}^{-1}-400 \mathrm{~cm}^{-1}$. Individually, Small amounts of native and modified Cassia gum with $\mathrm{KBr}$ was compressed in pellets using IR hydraulic press (CAP-15 T, PCI Analytics, Mumbai, India).

\subsubsection{X-Ray diffraction analysis (XRD).}

Cassia gum powder and carboxymethylated Cassia gum powder were also characterized by the diffraction patterns with nickel filters obtained by XRD (Miniflex 2, Rigaku, Japan). Both samples were fixed on glass holders and scanned at an approximate spectrum of $10^{\circ}-80^{\circ}$ diffraction angle $(2 \theta)$ with a processing rate of $0.05 / \mathrm{min}$, where, the voltage was $30 \mathrm{kV}$ and the current was $15 \mathrm{~mA}$.

\subsection{Preparation of microwave cross-linked carboxymethylated Cassia gum beads.}

The interaction between carboxymethylated Cassia gum and calcium ion was explored by preparing ionically gelled carboxymethylated Cassia gum beads in which diclofenac sodium was used as a model drug. An aqueous solution of carboxymethylated Cassia gum $(0.5 \mathrm{~g})$ containing diclofenac $(100 \mathrm{mg})$ was added drop by drop into the calcium chloride $\left(\mathrm{CaCl}_{2}\right)$ solution $(10 \% \mathrm{w} / \mathrm{v})$ using sterile syringe. The prepared beads were kept in $\mathrm{CaCl}_{2}$ solution for 5 
minute to complete the gel process and dried in the oven. After drying, prepared beads (200 $\mathrm{mg}$ ) were modified in household microwave (MH-6348BS, LG Electronics India Pvt. Ltd., India) at variable power $(160,320,480$ and $640 \mathrm{~W})$ where the optimized power $(480 \mathrm{~W})$ was selected and beads were modified [22]. After successful microwave cross-linking of carboxymethylated Cassia gum beads, the comparison of the release rate of carboxymethylated Cassia gum beads with microwave cross-linked beads was carried out to confirm the cross linking.

2.5. Evaluation of carboxymethylated Cassia gum beads with microwave cross-linked carboxymethylated Cassia gum beads.

\subsubsection{Fourier Transform-Infrared spectral analysis (FT-IR).}

$\mathrm{KBr}$ pellet technique was employed to record the FT-IR spectra of diclofenac sodium drug loaded carboxymethylated Cassia gum beads and microwave cross-linked carboxymethylated Cassia gum beads. Required amount of both beads ( $2 \mathrm{mg}$ ) were precisely weighed and triturated in pestle and mortar with $\mathrm{KBr}(100 \mathrm{mg})$ individually. In IR hydraulic presses $\left(80 \mathrm{~kg} / \mathrm{cm}^{2}\right)$ (CAP-15 T, PCI Analytics, Mumbai, India), the mixture was pressed into pellets for $30 \mathrm{sec}$. Scans between $4000 \mathrm{~cm}^{-1}$ and $400 \mathrm{~cm}^{-1}$ were recorded for spectral analysis (IR Affinity-I, Shimadzu, Japan).

\subsubsection{Determination of Entrapment efficiency.}

The total entrapment of drug, diclofenac sodium was determined spectrophotometrically at wavelength $276 \mathrm{~nm}$, which is present in weighed quantities of dried beads (Cary 5000. Varian, Australia). In the phosphate buffer (pH 6.8) solution, $100 \mathrm{mg}$ beads were smashed and digested under the probe sonicator (Q55, Q Sonica, USA) to an intensity of $55 \%$ over five minute. Then, filter out the dispersed particles and analyze the filtrate for drug content. Further, the efficiency of trapping (EE) was calculated using equation:-

$$
\% \text { Entrapment Efficiency }=\frac{\text { amount of diclofenac found in beads }}{\text { Total diclofenac used in the preparation of beads }} * 100
$$

\subsubsection{In vitro release behaviour.}

By utilizing USP Type-II dissolution apparartus (TDL-08L. Electrolab. India), a comparative in vitro release analysis of carboxymethylated Cassia gum beads with microwave cross-linked carboxymethylated Cassia gum beads were conducted. Beads (equal to $100 \mathrm{mg}$ of drug) were put into muslin cloth and tied on paddle in a dissolution apparatus filled with phosphate buffer (1000 ml, $\mathrm{pH} 6.8)$. The temperature was maintained of $(37 \pm 0.5)^{\circ} \mathrm{C}$ at $50 \mathrm{rpm}$ for $24 \mathrm{~h} .5 \mathrm{ml}$ of sample aliquots were removed at periodic intervals and substituted by equivalent new medium quantity. Using UV-spectrophotometer (Cary 5000, Varian, Australia), the obtained samples were evaluated at $274 \mathrm{~nm}$ for the content of diclofenac sodium [13].

\section{Results and Discussion}

Carboxymethylated Cassia gum, so obtained, was found to be off-white color and odourless. The results of degree of substitution $\left(\mathrm{Y}_{1}\right)$ of various batches of prepared carboxymethylated Cassia gum as per the design protocol are presented in Table 1. 
Table 1. Evaluation of various batches of carboxymethylated Cassia gum prepared as per central composite design.

\begin{tabular}{l|c|c|c|c} 
Run & Microwave Power $(\mathbf{W})\left(\boldsymbol{X}_{\mathbf{1}}\right)$ & $\begin{array}{c}\text { Microwave Time } \\
(\text { minute })\left(\boldsymbol{X}_{\mathbf{2}}\right)\end{array}$ & $\begin{array}{c}\text { Degree of substitution } \\
\left(\boldsymbol{Y}_{\mathbf{1}}\right)\end{array}$ & Percent yield $(\boldsymbol{\%})$ \\
\hline 1 & 50 & 2.5 & 0.986 & 96.1 \\
\hline 2 & 100 & 2.5 & 0.871 & 98.7 \\
\hline 3 & 150 & 2.5 & 0.711 & 99.5 \\
\hline 4 & 50 & 5 & 0.387 & 91.4 \\
\hline 5 & 100 & 5 & 0.429 & 97.9 \\
\hline 6 & 150 & 5 & 0.049 & 79.5 \\
\hline 7 & 50 & 7.5 & 2.592 & 79.1 \\
\hline 8 & 100 & 7.5 & 2.250 & 78.2 \\
\hline 9 & 150 & 7.5 & 2.592 & 91 \\
\hline 10 & 100 & 5 & 0.227 & 89.4 \\
\hline 11 & 100 & 5 & 0.429 & 88.8 \\
\hline 12 & 100 & 5 & 0.430 & 89
\end{tabular}

The results were fitted in various polynomial models and it was observed that the response $\left(\mathrm{Y}_{1}\right)$ i.e. degree of substitution fitted best into the quadratic response surface model. The polynomial model for the response $Y_{1}$ can be expressed by following equation.

$Y_{1}=4.50826-0.004243 X_{1}-1.86759 X_{2}+0.000550 X_{1} X_{2}-2.75 \times 10^{-6} X_{1}^{2}+0.213699 X_{2}^{2}$

On subjecting the polynomial model to ANOVA analysis, the model was found to be significant $(\mathrm{P}<0.05)$ with non-significant lack of fit $(\mathrm{P}>0.05)$ as shown in table 2 . The $\mathrm{R}^{2}$ value for response $Y_{1}$ is 0.9839 . Adequate precision measures the signal to noise ratio while the ratio of 22.218 indicates an adequate signal. Thus, the model can be used to navigate the design space.

Table 2. The coefficient estimate and the P-values of different variables of carboxymethylated Cassia gum.

\begin{tabular}{l|c|c}
\multirow{2}{*}{ Factor } & \multicolumn{2}{|c}{$\mathrm{Y}_{1}$} \\
\cline { 2 - 3 } & Estimate & P-value \\
\hline $\mathrm{X}_{1}$ & -0.1022 & 0.1419 \\
\hline $\mathrm{X}_{2}$ & 0.8110 & 0.0001 \\
\hline $\mathrm{X}_{1} \mathrm{X}_{2}$ & 0.0688 & 0.3934 \\
\hline $\mathrm{X}_{1}{ }^{2}$ & -0.0069 & 0.9418 \\
\hline $\mathrm{X}_{2}{ }^{2}$ & 1.34 & 0.0001
\end{tabular}

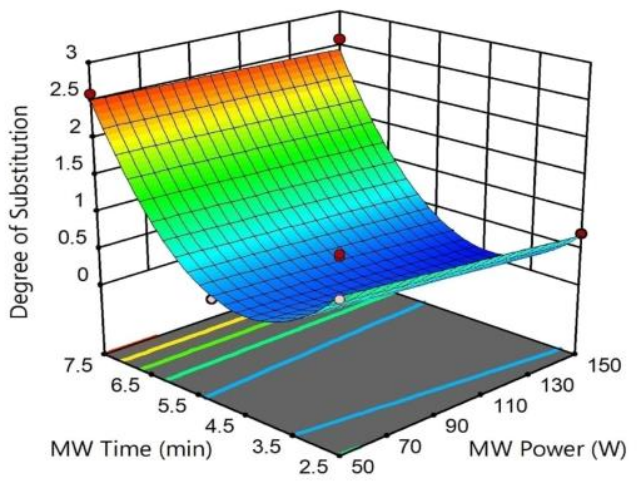

Figure 1. Response surface plot indicating combined response of microwave power and time of exposure on degree of substitution.

It can be observed that the response $\mathrm{Y}_{1}$ is affected significantly by the significant synergistic linear and quadratic contributions of $\mathrm{X}_{2}$. Figure 1 illustrates the 3-dimensional response surface plot showing the combined effect of microwave power $\left(\mathrm{X}_{1}\right)$ and microwave time $\left(\mathrm{X}_{2}\right)$. 
It was also observed that the influence of microwave time on degree of substitution is much greater than the influence of microwave power. Further, there is a curvilinear relationship between microwave exposure time and degree of substitution. As, microwave exposure time gets increased from 2.5 to 7.5 minutes, there was a slight decrease in the degree of substitution but further increase in microwave exposure time increased the degree of substitution. Thus, greater the microwave exposure, greater was the degree of substitution. Further, numerical optimization was done through Design Expert Software, which gives three solutions. So, the optimal parameters were found to be microwave power of $50 \mathrm{~W}$ and microwave exposure time of 7.36 minutes which provided carboxymethylated gum with a degree of substitution of 2.5 (predicted 2.3). Thus, the proposed model is suitable for synthesizing products with desired degree of substitution.

\subsection{Characterization of carboxymethylated Cassia gum.}

\subsubsection{FT-IR spectroscopy.}

Figure 2 depicts the FT-IR spectra of crude Cassia gum with carboxymethylated Cassia gum. In IR spectra of Cassia gum, broad absorption band at $3424.67 \mathrm{~cm}^{-1}$ is due to $\mathrm{O}-\mathrm{H}$ stretching. Absorption peak originating at $2878.80 \mathrm{~cm}^{-1}$ is due to $\mathrm{C}-\mathrm{H}$ stretching vibrations of alkanes. The peaks appearing at $1667 \mathrm{~cm}^{-1}$ and $1164 \mathrm{~cm}^{-1}$ owing to $\mathrm{C}=\mathrm{O}$ stretching vibration (asymmetric) and C-O-C stretching respectively. On the other hand, the IR spectra of carboxymethylated Cassia gum showed absorptive pattern with characteristics absorption peak at $3441.06 \mathrm{~cm}^{-1}$ is due to $\mathrm{O}-\mathrm{H}$ stretching. Peaks at $2920.27 \mathrm{~cm}^{-1}$ and $2853.73 \mathrm{~cm}^{-1}$ are due to C$\mathrm{H}$ stretching of alkanes. The peak appearing at $1735.96 \mathrm{~cm}^{-1}$ is due to $\mathrm{C}=\mathrm{O}$ stretching while the extra peak at $1616.37 \mathrm{~cm}^{-1}$ and $1418.31 \mathrm{~cm}^{-1}$ is attributed to $\mathrm{C}=\mathrm{O}$ stretching and carboxylate anions confirm the addition of carboxymethyl group on Cassia gum. Also, Peak at $1026.14 \mathrm{~cm}^{-}$ ${ }^{1}$ can be due to $\mathrm{C}-\mathrm{O}$ stretching of $-\mathrm{C}-\mathrm{O}-\mathrm{C}-[23]$.

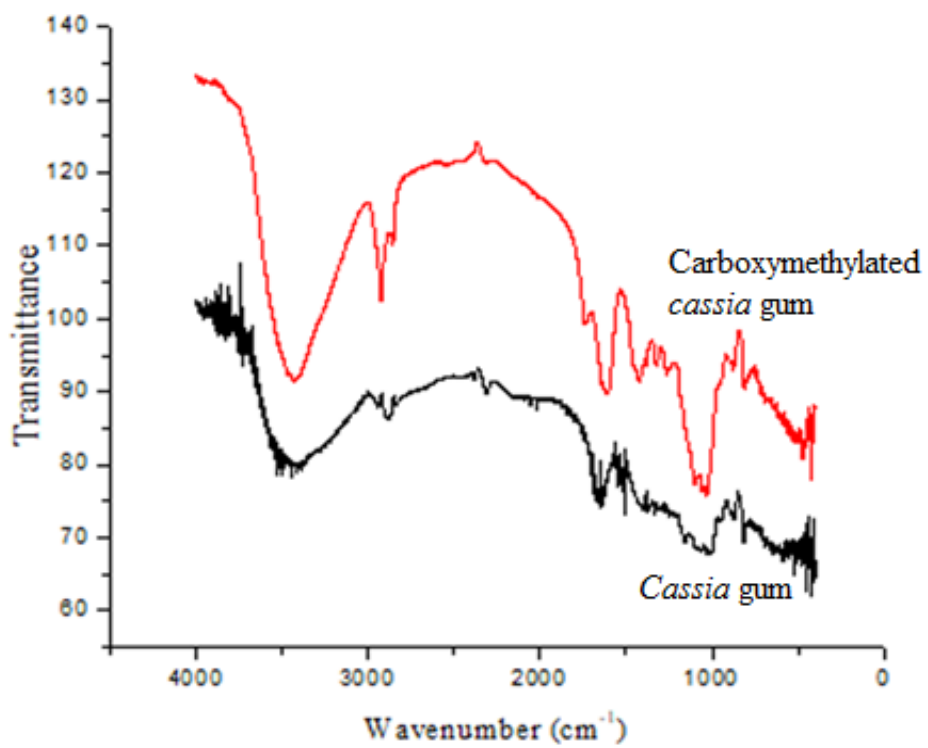

Figure 2. FT-IR spectra of Cassia gum and carboxymethylated Cassia gum.

\subsubsection{X-Ray diffraction analysis (XRD).}

Figure 3 displays the X-Ray diffractogram of Cassia gum and carboxymethylated Cassia gum. X-Ray diffraction spectra of Cassia gum are typical of amorphous material. On the other hand, microwave assisted carboxymethylated Cassia gum displays sharp peak at 
$16.74^{\circ}, 24.3^{\circ}(2 \theta)$ which indicates a slight increase in crystallinity of Cassia gum on carboxymethylation.

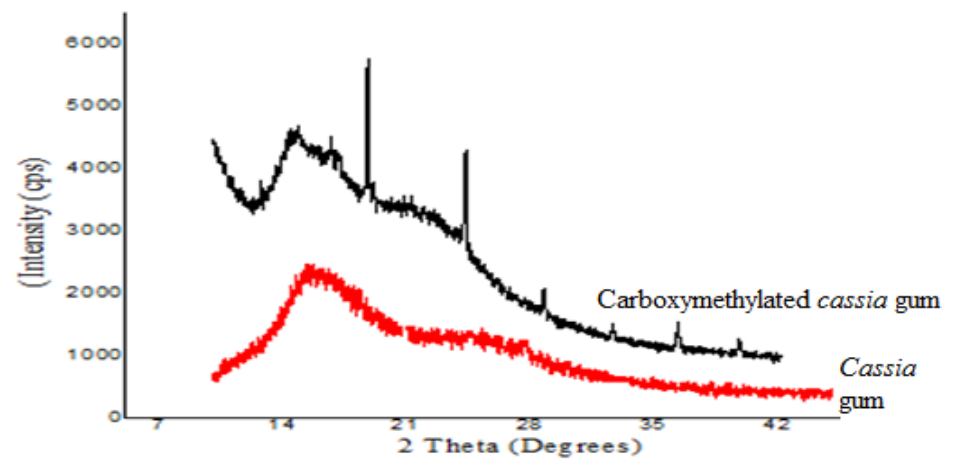

Figure 3. XRD spectra of Cassia gum and carboxymethylated Cassia gum

\subsubsection{Pharmaceutical evaluation of beads.}

Carboxymethylation of Cassia gum imparts anionic character on the gum; as a result, it interacts with calcium ions to form gels. This property was used to prepare ionically gelled beads of diclofenac which was used as the model drug. Further, it had already been reported that microwaves can be used to tailor the release of drugs from beads by inducing cross-linking [22]. In the present study, the beads prepared were cross-linked by treatment with microwave exposure at different powers. The beads cross-linked at less than $480 \mathrm{~W}$ were found to erode at a faster pace while beads cross-linked on more than or equal to $480 \mathrm{~W}$ power were found to be porous, so cross-linking at $480 \mathrm{~W}$ was considered satisfactory.

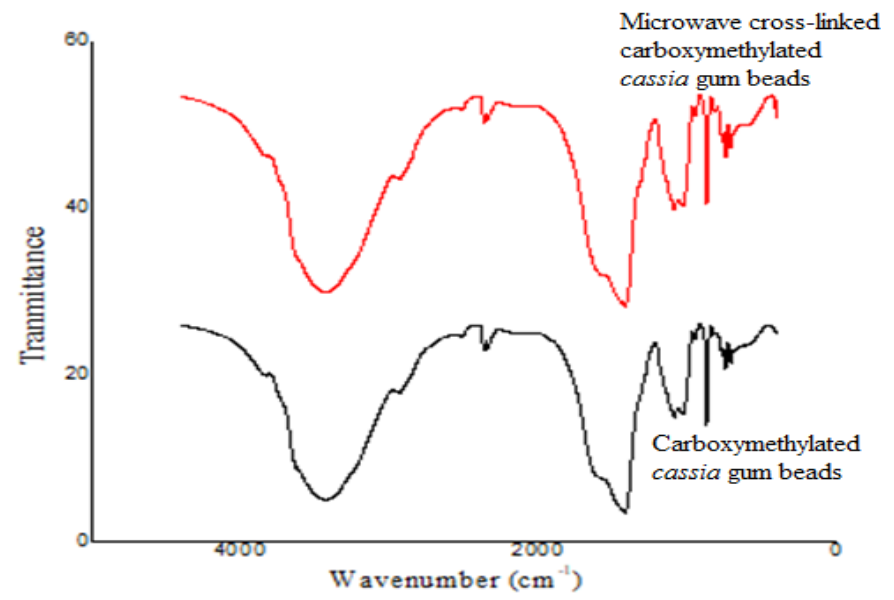

Figure 4. FT-IR spectra of carboxymethylated Cassia gum beads and microwave cross-linked Cassia gum beads.

\subsubsection{FT-IR spectra of beads.}

The FT-IR spectra of carboxymethylated Cassia gum beads (Figure 4) showed the broad absorption band at $3455.43 \mathrm{~cm}^{-1}$ can be due to $\mathrm{OH}$ stretching and absorption peak originated at $2628.64 \mathrm{~cm}^{-1}$ due to $\mathrm{C}-\mathrm{H}$ stretching vibrations of alkanes. Peaks at $1629.37 \mathrm{~cm}^{-1}$ and $1420.05 \mathrm{~cm}^{-1}$ are due to $\mathrm{C}=\mathrm{O}$ asymmetric stretching vibrations of carboxylic acid of glucuronic acid while at $1061.61 \mathrm{~cm}^{-1}$, peak was seen which can be due to $\mathrm{C}-\mathrm{O}-\mathrm{C}$ stretching. The FT-IR spectra of microwave cross-linked carboxymethylated Cassia gum beads showed absorptive pattern with a characteristic absorption peak at $3422.45 \mathrm{~cm}^{-1}$ and $2628.94 \mathrm{~cm}^{-1}$ is due to $\mathrm{OH}$ stretching and $\mathrm{C}-\mathrm{H}$ stretching of alkanes respectively. The peaks appearing at 
$1614.31 \mathrm{~cm}^{-1}$ is attributed to $\mathrm{C}=\mathrm{O}$ stretching while the peak at $1420.02 \mathrm{~cm}^{-1}$ and $1063.02 \mathrm{~cm}^{-1}$ corresponds to carboxylate anions and C-O stretching of -C-O-C respectively [24].

\subsubsection{Entrapment efficiency.}

The entrapment efficiency of diclofenac sodium in carboxymethylated Cassia gum beads and microwave cross-linked carboxymethylated Cassia gum beads were found to be $64.4 \%$ and $61.7 \%$ respectively. Thus, it was concluded that there was no significant change of microwave exposure on the drug content of beads.

\subsubsection{In vitro drug release.}

The in vitro drug release of diclofenac sodium loaded microwave assisted carboxymethylated Cassia gum beads and microwave cross-linked carboxymethylated Cassia gum beads are shown in Figure 5. It was observed that almost $100 \%$ of the drug got release within 60 minutes for both carboxymethylated Cassia gum beads and microwave cross-linked carboxymethylated Cassia gum beads. Thus, no significant difference in in vitro drug release was observed on treatment with microwave radiation. During an earlier study, microwave exposure of chitosan beads was also reported to modify the release of drug due to cross-linking induced by microwaves [22]. However, in the present study not such effect was observed.

To determine the kinetics and release mechanism, the data was analysed to various models i.e. zero order, first order, Higuchi and Korsmeyer-Peppas. The $\mathrm{R}^{2}$ values for zero order, first order, Higuchi and Korsmeyer-Peppas release kinetics were found to be 0.919, $0.268,0.457$ and 0.726 respectively for carboxymethylated Cassia gum beads, while for the carboxymethylated Cassia gum beads cross-linked using microwave showed respective $\mathrm{R}^{2}$ value of $0.923,0.241,0.419$ and 0.690 respectively. The results thus indicate that the release of diclofenac from the beads follows zero order kinetics. Further, the value of release exponent ( $n$ ) for carboxymethylated Cassia gum beads and microwave cross-linked carboxymethylated Cassia gum beads were found to be 0.82 and 0.78 respectively, which points to the anomalous release mechanism i.e. combination of erosion and diffusion.

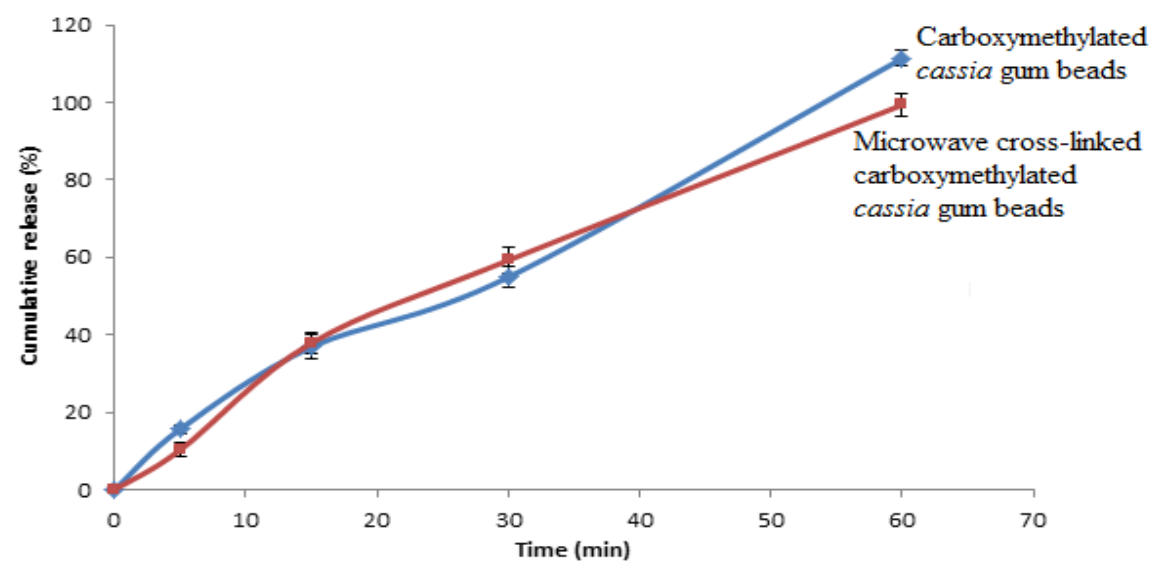

Figure 5. In vitro release profiles of carboxymethylated Cassia gum beads and microwave cross-linked carboxymethylated Cassia gum beads.

\section{Conclusions}

Carboxymethylation of Cassia gum was achieved by employing microwave assisted technique. The response surface methodology was used to optimize the effect of microwave power and microwave exposure time on the degree of substitution. FT-IR and XRD 
investigations confirmed the carboxymethylation of Cassia gum where XRD results indicated that carboxymethylation of Cassia gum imparts crystallinity to the inherent amorphous cassia gum. The obtained carboxymethylated Cassia gum was finally formulated into ionically gelled beads and further evaluated for pharmaceutical applications. The prepared beads were also treated with microwave exposure to modify the release behavior. However, no significant influence of microwave exposure on the release behavior of $\mathrm{Ca}^{2+}$ - gelled carboxymethyl Cassia gum was observed. On the basis of the results of our study, it can be concluded from that microwave assisted carboxymethyl modification of Cassia gum can be utilized to derive a polymeric material with potential pharmaceutical applications.

\section{Funding}

This research received no external funding.

\section{Acknowledgments}

The author express gratitude to Central instrumental laboratory, GJUS\&T, Hisar for the facility of Microwave synthesis reactor, and Department of Physics, GJUS\&T, Hisar for facility of XRD.

\section{Conflicts of Interest}

The authors declare no conflict of interest.

\section{References}

1. Wu, D.T.; Liu, W.; Han, Q.H.; Wang, P.; Xiang, X.R.; Ding, Y.; Zhao, L.; Zhang, Q.; Li, S.Q.; Qin, W. Extraction Optimization, Structural Characterization, and Antioxidant Activities of Polysaccharides from Cassia Seed (Cassia obtusifolia). Molecules 2019, 24, 1-16, https://doi.org/10.3390/molecules24152817.

2. Paudel, P.; Seong, S.H.; Shrestha, S.; Jung, H.A.; Choi, J.S. In Vitro and in Silico Human Monoamine Oxidase Inhibitory Potential of Anthraquinones, Naphthopyrones, and Naphthalenic Lactones from Cassia obtusifolia Linn Seeds. ACS Omega 2019, 4, 16139-16152, https://doi.org/10.1021/acsomega.9b02328.

3. Meng, Y.; Liu, Y.; Fang, N.; Guo, Y. Hepatoprotective effects of Cassia semen ethanol extract on nonalcoholic fatty liver disease in experimental rat. Pharmaceutical Biology 2019, 57, 98-104, https://doi.org/10.1080/13880209.2019.1568509.

4. Hou, J.; Gu, Y.; Zhao, S.; Huo, M.; Wang, S.; Zhang, Y.; Qiao, Y.; Li, X. Anti-Inflammatory Effects of Aurantio-Obtusin from Seed of Cassia obtusifolia L. through Modulation of the NF- $\kappa$ B Pathway. Molecules 2018, 23, 1-15, https://doi.org/10.3390/molecules23123093.

5. Prajapati, V.D.; Jani, G.K.; Moradiya, N.G.; Randeria, N.P. Pharmaceutical applications of various natural gums, mucilages and their modified forms. Carbohydrate Polymers 2013, 92, 1685-1699, https://doi.org/10.1016/j.carbpol.2012.11.021.

6. Huanbutta, K.; Sittikijyothin, W. Use of seed gums from Tamarindus indica and Cassia fistula as controlledrelease agents. Asian Journal of Pharmaceutical Sciences 2018, 13, 398-408, https://doi.org/10.1016/j.ajps.2018.02.006.

7. Jang, S.H.; Yang, D.K. The combination of Cassia obtusifolia L. and Foeniculum vulgare M. exhibits a laxative effect on loperamide-induced constipation of rats. PLOS ONE 2018, 13, 1-13, https://doi.org/10.1371/journal.pone.0195624.

8. Sharma, B.R.; Kumar, V.; Soni, P.L.; Sharma, P. Carboxymethylation of Cassia tora gum. Journal of Applied Polymer Science 2003C, 89, 3216-3219, https://doi.org/10.1002/app.12430.

9. Sharma, B.R.; Kumar, V.; Soni, P.L. Cyanoethylation of Cassia tora gum. Starch/Starke 2003b, 55, 38-42, https://doi.org/10.1002/star.200390004,

10. Sharma, B.R.; Kumar, V.; Soni, P.L. Carbamoylethylation of Cassia tora gum. Carbohydrate Polymers 2003a, 54, 143-147, https://doi.org/10.1016/S0144-8617(03)00132-2.

11. Sharma, B.R.; Kumar V.; Soni, P.L. Graft copolymerization of acrylamide onto Cassia tora gum. Journal of Applied Polymer Science 2002, 86, 3250-3255.

12. Liu, M.; Niu, C.; Shaoying, L.I. Synthesis and characterization of carboxymethyl Cassia tora gum. Journal of Hebei University of Science \& Technology 2014, 35, 548-554. 
13. Rani, D.; Ahuja, M. Carboxymethylation of Lepidium sativum polyuronide, its characterization and evaluation as a nanometric carrier. International Journal of Biological Macromolecules 2017, 99, 233-240, https://doi.org/10.1016/j.ijbiomac.2017.02.036.

14. Theis, V.T.; Santos, Q.A.V.; Appelt, P.; Barbosa-Dekker, M.A.; Vetvicka, V.; Dekker, H.F.R.; Cunha, A.A.M. Fungal exocellular(1-6)- $\beta$-D-glucan: Carboxymethylation, characterization, and antioxidant activity. International Journal of Molecular Sciences 2019, 20, 1-15, https://doi.org/10.3390/ijms20092337.

15. Rimpy; Abhishek, R; Ahuja, M. Evaluation of carboxymethyl Moringa gum as nanometric carrier. Carbohydrate Polymers 2017, 174, 896-903, https://doi.org/10.1016/j.carbpol.2017.07.022.

16. Brhane Y. Evaluation of carboxymethylated plectranthus edulis starch as a suspending agent in metronidazole benzoate suspension formulations. PLOS One 2020, 15(3), 1-17, https://doi.org/10.1371/journal.pone.0228547

17. Malik. S.; Ahuja. M. Gum kondagogu-g-poly (acrylamide): Microwave-assisted synthesis, characterization and release behavior. Carbohydrate Polymers 2011, 86, 177-184, https://doi.org/10.1016/j.carbpol.2011.04.027.

18. Sun, H.; Shao, X.; Jiang, R.; Ma, Z.; Wang, H. Effects of ultrasonic/microwave-assisted treatment on the properties of corn distarch phosphate/corn straw cellulose films and structure characterization. Journal of Food Science \& Technology 2018, 55, 1467-1477, https://doi.org/10.1007/s13197-018-3063-8.

19. Abhishek; Rimpy; Ahuja, M. Moringa gum-g-poly( $N$-vinyl-2-pyrrolidone) - a potential buccoadhesive polymer. International Journal of Biological Macromolecules 2018, 109, 732-739, https://doi.org/10.1016/j.ijbiomac.2017.12.112.

20. Meenakshi; Ahuja, M.; Verma, P. MW-assisted synthesis of carboxymethyl tamarind kernel polysaccharideg-polyacrylonitrile, optimization and characterization. Carbohydrate Polymers 2014, 113, 532-538, https://doi.org/10.1016/j.carbpol.2014.07.041.

21. Eyler, R.W.; Klug, E.D.; Diephuis, F. Determination of degree of substitution of sodium carboxymethylcellulose. Analytical Chemistry 1947, 19, 24-27, https://doi.org/10.1021/ac60001a007.

22. Nurjaya, S.; Wong, T.W. Effects of microwave on drug release properties of matrices of pectin. Carbohydrate Polymers 2005, 62, 245-257, https://doi.org/10.1016/j.carbpol.2005.07.029.

23. Kumar, D.; Mundlia, J.; Kumar, T.; Ahuja, M. Silica coating of carboxymethyl tamarind kernel polysaccharide beads to modify the release characteristics. International Journal of Biological Macromolecules 2019, 146, 1040-1049, https://doi.org/10.1016/j.ijbiomac.2019.09.229.

24. Minkal; Ahuja, M.; Bhatt, C.D. Polyelectrolyte complex of carboxymethyl gum katira-chitosan: preparation and characterization. International Journal of Biological Macromolecules 2018, 106, 1184-1191, https://doi.org/10.1016/j.ijbiomac.2017.08.128. 